\title{
The Early and Mid-Term Follow-up of Drug Eluting Balloon (DEB) For Below the Knee Angioplasty: An Observational Study
}

\author{
MOHAMMED ALI, M.D. and MAHMOUD NASSER, M.D. \\ The Department of Vascular Surgery, Faculty of Medicine, Cairo University
}

\begin{abstract}
Background: Re-stenosis following infra-popliteal angioplasty could results in many serious consequences like recurrence of ischemic symptoms or break through of wound healing. With the evolving techniques of Paclitaxil release and the rapid advancement in the manufacturing of endovascular equipment, drug eluting balloons emerge as a useful option to overcome intimal hyperplasia and subsequent restenosis.

Aim of Study: To highlight the clinical impact of additional DEB application in patients with CLI attributed to infrapopliteal disease regarding the re-stenosis rate, amputation free survival and limb salvage.
\end{abstract}

Material and Methods: This study is prospective observational study over a period of one year including 33 patients who underwent infra-popliteal angioplasty using DEB

Results: 33 patients (36 limbs) were included in the study, 24 cases ( 27 limbs) were presented by a re-stenosis or occlusion after previous trial of angioplasty using plain balloon, while 9 patients come with the first presentation (Denovo lesions). Stenotic lesions were found in 21 limbs $(58.3 \%)$ while occlusive lesions were observed in 9 limbs $(25 \%)$ and combined stenotic and occlusive lesions were found in 6 limbs (16.7\%). The mean length of the treated lesions within the tibial arteries using DEB was $7.6 \pm 3.4 \mathrm{~m}$. Primary patency rate at 3,6 and 12 months was $91.3 \%, 82.6 \%$ and $70.9 \%$. While limb salvage rate at 3,6 and 12 months was $91.6 \%, 81.8 \%$ and $72.8 \%$ respectively.

Conclusion: With the rapid advancement in the endovascular tools \& equipment, the early results is encouraging and promising with additional application of DEB for patients with infra-popliteal arterial disease in comparison to the traditional use of plain uncoated balloons. However, the midterm and late results of the IN.PACT DEEP study suggest that an extreme caution is to be considered in this field.

Key Words: Drug eluting balloon - Peripheral vascular disease - Re-stenosis - Below the knee angioplasty.

Correspondence to: Dr. Mohammed Ali, The Department of Vascular Surgery, Faculty of Medicine, Cairo University

\section{Introduction}

INFRA-POPLITEAL angioplasty combined with an adequate wound care program has been considered as an accepted modality for limb preservation. However, re-do endovascular interventions for infra-popliteal disease to overcome re-stenosis could be associated with high morbidity and mortality rates [1-3]

Intimal Hyperplasia (IH) with subsequent restenosis is a serious problem that has a major impact on the outcome of endovascular intervention. $40-60 \%$ of the treated cases reported restenosis after 1 year. Local application of antiproliferative agents, such as taxols, has been used as the rationale to start using the drug-eluting stents and Drug-Eluting Balloons (DEBs) [4] .

With the new update in Trans-Atlantic Intersociety Consensus (TASC) classification, the new infra-popliteal lesion classification started to incorporate different features that attempt to address the multi-vessel lesions of infra-popliteal arteries [5].

In most of scenarios, lesions that involve single tibial vessel rarely lead to development of a clinical symptoms or signs. So in order to develop a clinical presentation, a significant reduction in the lower limb perfusion should occur, which usually occurred when the disease involves multiple levels of the tibial arteries [6]

Drug-eluting stents have been agreed to be an accepted solution for treatment of focal lesions of the infra-popliteal arterial disease $[\mathbf{7 , 8 ]}$. However, because of the diffuse pattern of atherosclerotic disease involving below-the-knee vessels the use of these stents in these situations is questionable [8] with the advancement of the drug eluting technology, balloons coated with paclitaxel have 
emerged as an alternative and a more valid treatment solution in patients with peripheral arterial disease, [9] especially after the marvelous and encouraging results for its application in the femoro-popiteal segment $[\mathbf{9 , 1 0 ]}$.

\section{Material and Methods}

This is a prospective observational study over a period of one year, in which a special predetermined protocol was applied in all patients evaluating the effectiveness of DEB in reducing the early and mid-term Re-stenosis Rate (RR) when used for treatment of below the knee vessels, and this protocol consists of the following steps:

This study was conducted between 2016-2018 at Kasr Al-Ainy and New Kasr Al-Ainy Teaching Hospitals.

Patients with Critical Limb Ischemia (CLI) and below the knee lesions either stenosis more than $70 \%$ or occlusions were included in the study and were treated with a Paclitaxel Eluting Balloon.

The balloon is coated with FreePac technology system, which is a proprietary formulation of $3.0 \mu \mathrm{g}$ paclitaxel $/ \mathrm{mm}^{2}$ and urea, serving as a hydrophilic spacer aiming to make the separation and release of paclitaxel molecules within the arterial wall much easier.

Dual antiplatelet therapy "Aspirin" (100mg/d) and "Clopidogrel" $(75 \mathrm{mg} / \mathrm{d})$ was given before the procedure, antibiotics were administered in presence of infection, and all procedures were performed using local anesthesia.

Access was achieved via an ipsilateral common femoral artery using 6Fr sheath, and intravenous bolus administration of 5000IU of unfractionated heparin was given within the sheath.

Diagnostic angiography through a selective catheter placed at the lower popliteal segment and Digital Subtraction Angiography (DSA) should be done in at least two views with prolonged imaging time to allow adequate filling time of the collateral circulation.

A high frame rate of $4 \mathrm{fps}$ is recommended in order to get the best view of the filling of the collaterals and to easily discriminate between the overlapping vessels through their differential filling time. Adequate time interval should be given to ensure adequate wash of the contrast from the slowly filling collateral vessels.

Engagement of the ostium of the tibial vessel can be achieved with the aid of road mapping while using 4Fr curved tip catheter, careful crossing of the lesion with either subintimal or transluminal passage using a 0.018 inch guidewire.

Wire choice can be based according to anatomical characteristics of the tibial vessel. Whenever the tibial artery have a relatively straight course, a hydrophilic 0.018 -inch guidewire will be useful to cannulate the lesion. A low-weight 0.018-inch CTO guidewire can be helpful if there is a side branch just at the beginning of occlusion that can make the passage of the hydrophilic wire quite difficult [23].

Failure to achieve antegrade crossing of the lesion can raise the possibility of the duplex guided retrograde access of either dorsalis or posterior tibial artery and trial to traverse the lesion in a retrograde fashion.

After successful crossing of the lesion, the target tibial artery was dilated using low profile plain balloon $2.5-3.0 \mathrm{~mm}$ plain balloon with an inflation pressure ranging between 6-8atm and inflation time between 30-120 seconds. Predilatation of tibial arteries is important to avoid a complicated passage of the DEB through the lesion.

The hydrophilic 0.018 or 0.035 was exchanged for 0.014 guide wire "compatible with most of the drug eluting balloons" which should be $0.5 \mathrm{~mm}$ larger in diameter than the balloon used for predilatation.

The plain balloon was exchanged for a drug eluting balloon, which was inflated for about 1-3 minutes to ensure maximum time for contact between the vessel wall and the balloon and make sure that the drug was fully released. Diameter range between $3.0-4.0 \mathrm{~mm}$ and length between 80 $120 \mathrm{~mm}$. If more than one DEB was planned to be used for one artery, a $5 \mathrm{~mm}$ overlap should be obtained.

100-300mcg of "Nitroglycrine" was administrated through the sheath and completion angiogram should be performed.

Angiographic success was clarified when at least one infra-popliteal artery was restored in continuity till the pedal planter arch of the foot with a residual stenosis of less than $30 \%$.

The patients were assessed clinically for the retrieved distal pulsation post procedural, rest pain relief, healing of wounds or ulcers and bleeding from amputation wounds. Also duplex evaluation was scheduled after 1, 6 and 12 months post procedural. 


\section{Results}

In this study, 33 patients (36 limbs) were included, and drug eluting balloons were used during tibial vessels angioplasty was performed according to the above mentioned protocol.

The clinical characteristics and patient demographics are given in Table (1).

Table (1): Patient demographics and associated comorbidities.

\begin{tabular}{lcc}
\hline Age & \multicolumn{2}{c}{$45-75($ mean $59 \pm 3$ years $)$} \\
\cline { 2 - 3 } Sex & $\begin{array}{c}\text { Male } \\
15(45.5 \%)\end{array}$ & $\begin{array}{c}\text { Female } \\
18(54.5 \%)\end{array}$ \\
\cline { 2 - 3 } Co-morbidities & No. & Percentage \\
\hline Hypertension & 12 & 36.3 \\
Diabetes & 24 & 72.7 \\
Smoking & 15 & 45.5 \\
Hyperlipidemia & 12 & 36.3 \\
Renal impairment & 9 & 27.3 \\
Bronchogenic carcinoma & 1 & 3 \\
\hline
\end{tabular}

The presentation was dry gangrene in 18 patients $(54.5 \%)$, foot infection or spreading gangrene involving the toes and the forefoot in 12 patients $(36.3 \%)$, infected wounds in 3 patients $(9.1 \%)$.

For patients included in this study, 24 cases (27 limbs) were presented by a re-stenosis or occlusion after previous trial of angioplasty using plain balloon, while 9 patients come with the first presentation (Denovo lesions).

Stenotic lesions were found in 21 limbs $(58.3 \%)$ while occlusive lesions were observed in 9 limbs $(25 \%)$ and combined stenotic and occlusive lesions were found in 6 limbs $(16.7 \%)$.

The pathological involvement of the tibial vessels was variable. According to the disease distribution and involvement, single tibial artery involvement was observed in 6 patients (have an associated supra-genicular lesion), two tibial vessels were affected in 24 patients ( 26 limbs) and all the three tibial vessels were involved in 3 patients.

The number of the treated arteries in this study was 57 arteries, and the number of used balloons was 69 balloons.

The mean length of the treated lesions within the tibial arteries using DEB was $7.6 \pm 3.4 \mathrm{~mm}$. For patients presented with restenosis of the tibial arteries using plain balloon the restenosis was usually focal and range between $20-50 \%$ of the original lesion length.
Table (2): Arterial segment involved.

\begin{tabular}{lcc}
\hline Artery \& involvement site & Number & Percentage \\
\hline $\begin{array}{l}\text { Supra-genicular or popliteal } \\
\text { artery lesions }\end{array}$ & 6 & 16.7 \\
Anterior tibial artery & 15 & 41.7 \\
Tibio-peroneal trunk & 6 & 16.7 \\
Posterior tibial artery & 24 & 66.8 \\
Peroneal artery & 9 & 25 \\
Proximal segment & 12 & 33.4 \\
Mid-segment & 27 & 75 \\
Distal segment & 18 & 50 \\
Multiple segments & 6 & 16.7 \\
\hline
\end{tabular}

Ipsilateral femoral antegrade access was used in all patients included in this study using $6 \mathrm{Fr}$ sheath. No retrograde access was required in this study.

A pre-planned decision was taken to use DEB for patients with recurrent lesions due to the presence of recoil of the arterial wall occurred after previous angioplasty. However, in patients with Denovo lesions the decision to use DEB was based on the angiographic appearance of their arterial wall as a regard the presence of an arterial wall dissection.

Patients were scheduled for regular follow-up at 3, 6 and 12 months.

During the follow-up at 3 months, one patient died due to an associated bronchogenic carcinoma. While the remaining patients had no symptoms, nearly complete wound healing "complete epithelialization of the wound".

At 6 month evaluation, 6 patients had lost the previously retrieved distal pulse by clinical examination and duplex evaluation documents focal restenosis of the previously dilated tibial artery. One of these patients had undergone angioplasty for two tibial arteries, but only one tibial artery developed restenosis while the other was patent, she was asymptomatic and she was managed conservatively by medical treatment. The rest of patients underwent angioplasty and DEB for one tibial artery only "single runoff tibial artery", they started to develop re-opening and breakdown of the healed wound or spreading gangrene, and they required re-do angioplasty with another DEB.

At one year, the same patients had lost the retrieved distal pulse one more time by clinical examination and duplex assessment showed reocclusion of the previously dilated tibial artery. Unfortunately these 5 patients develops extensive wound infection and ended up by below knee amputation. 
No procedure related complication apart from minor groin hematoma less than $3 \mathrm{~cm}$ in diameter in 2 patients and it was managed conservatively.
Primary patency rate at 3,6 and 12 months was $91.3 \%, 82.6 \%$ and $70.9 \%$. While limb salvage rate at 3,6 and 12 months was $91.6 \%, 81.8 \%$ and $72.8 \%$ respectively.
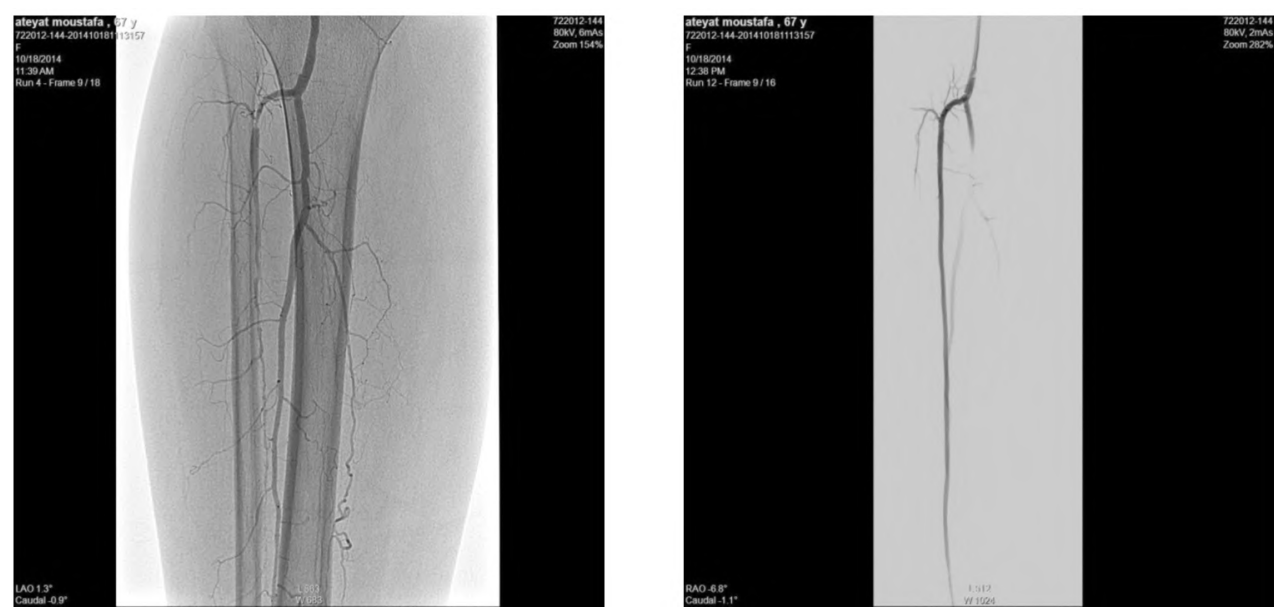

Fig. (1): Focal stenosis proximal anterior tibial artery following previous PTA using plain balloon, treated by DEB.
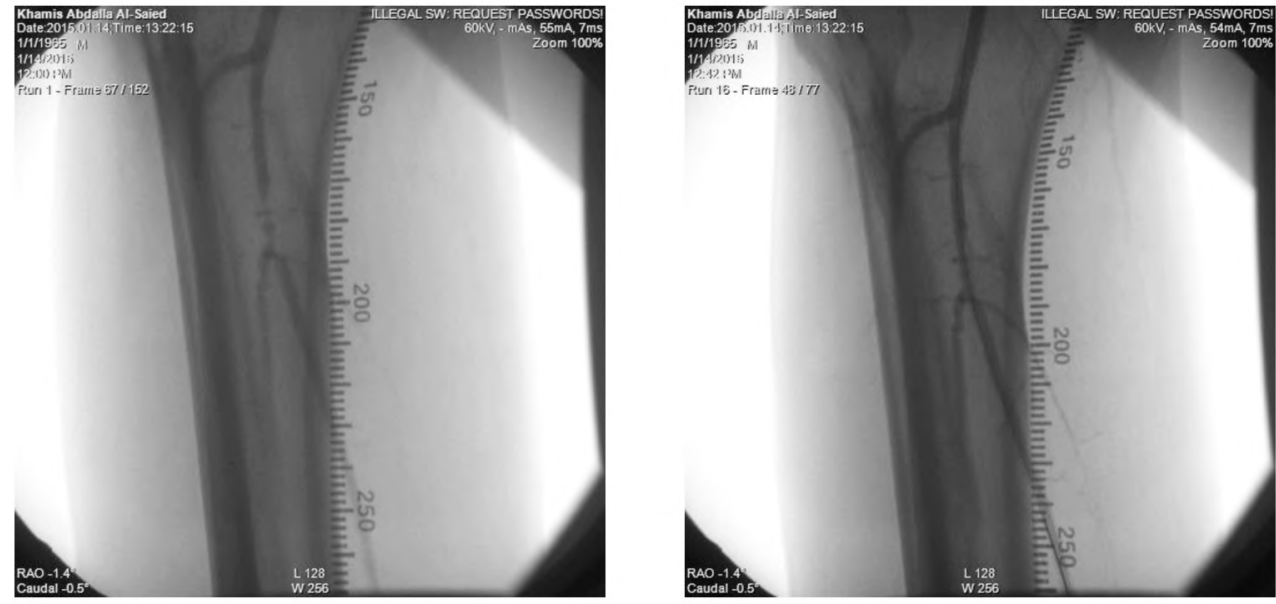

Fig. (2): Focal stenosis tibioperoneal trunk.
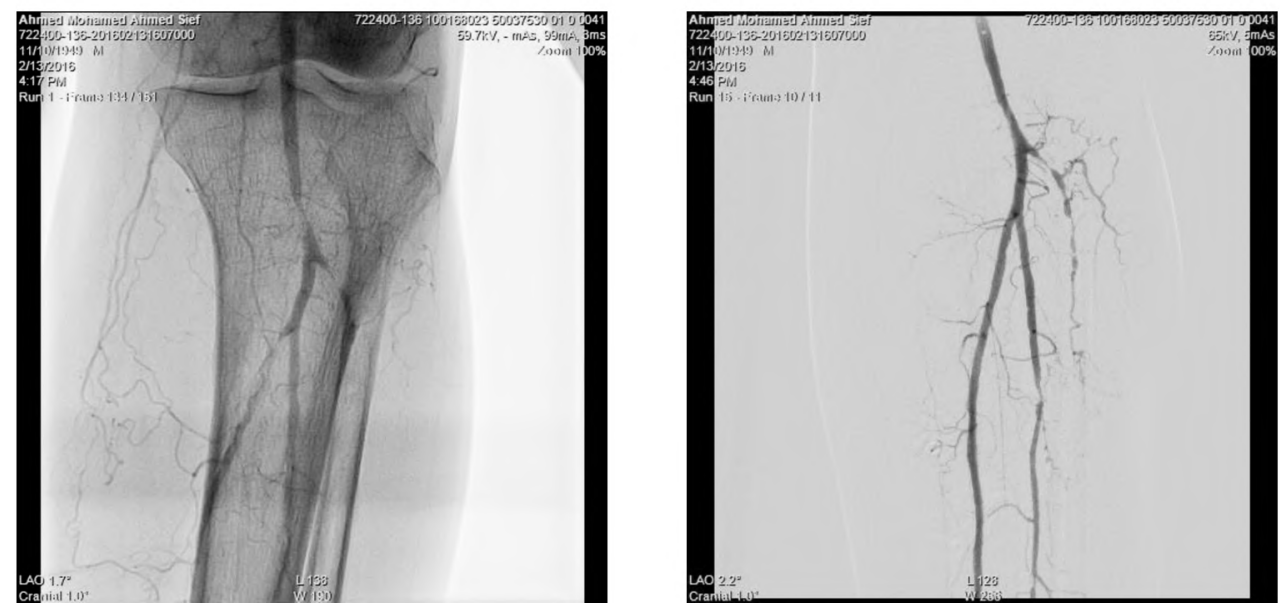

Fig. (3): Popliteal artery focal stenosis. 

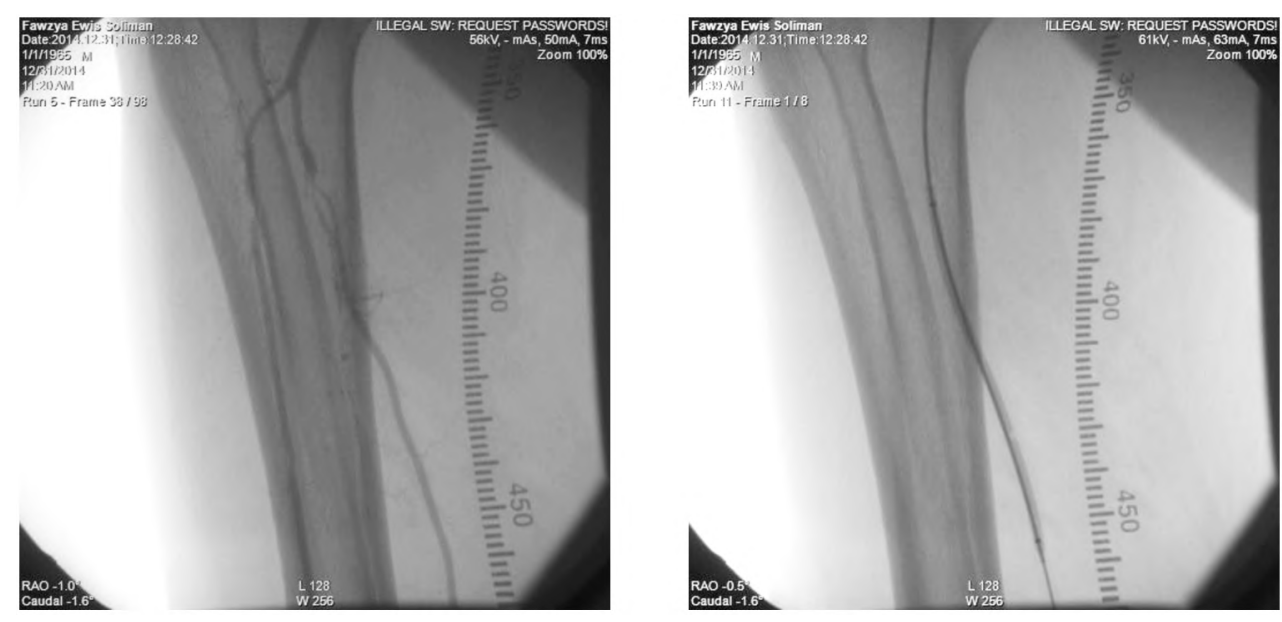

Fig. (4): Focal stenosis of proximal posterior tibial artery.

\section{Discussion}

Some technical considerations should be kept in mind while performing revascularization for infra-popliteal arteries using DEB. Several anatomical aspect in the below the knee arteries and specific pathophysiological criteria should be considered while performing infra-popliteal angioplasty. The tibial arteries are tapered as they go down towards the ankle. This tapering pattern may hinder the uniform distribution of the drug delivery when the DEB gets in contact with the arterial wall [21].

Theoretically speaking, because of the long way distance between the access to the arterial lesion below the knee and due to the small arterial diameter, it is a possible that the coated drug may get detached from the balloon during its delivery within BTK arteries [22,26].

Diabetic patients usually have extensive calcifications in the medial layer of their arterial wall. Many authors hypothesize that the presence of the medial calcification may be an obstacle for uniform uptake of the drug by the arterial wall [23-26] .

DEB at ankle and foot level are associated with a lower patency rate in comparison to its use for the proximal and mid segments of infra-popliteal arteries $[\mathbf{1 3 , 2 1 ]}$. This could be explained by the excess friction between the balloon surface and the small caliber arterial vessels during the manipulation resulting in insufficient drug coverage or a premature drug release before reaching the target lesion.

The restenosis rate was defined as a peak systolic velocity more than $2.4 \mathrm{~m} / \mathrm{s}$ or an intimal hyperplasia causing luminal stenosis more than $70 \%$ detected on duplex ultrasonography $[\mathbf{6 , 1 1}]$.
The restenosis rate following angioplasty for infra-popliteal arteries is usually frequent. Many published studies revealed that angioplasty for infra-popliteal arteries using plain uncoated balloons was associated with restenosis rate up to $69 \%$ after 3 months [12,13].

Many studies document different patterns of restenosis and they correlate these patterns for the type of balloons used for treating these lesions. Restenosis following the use of plain uncoated balloons usually involves the full length of the previously treated segment $[\mathbf{1 2 , 1 3}$, while restenosis following the use of DEB is usually focal, and it involve about $20 \%$ of the original length of the previously treated lesions [13].

The Drug Eluting Balloon in peripherAl inTErvention for Below The Knee "DEBATE-BTK" study is the first randomized study comparing the effectiveness of DEB and plain uncoated balloon in patients with CLI who is candidate for infrapopliteal angioplasty regarding the 1 year restenosis rate and TLR rate. In this study, DEB was associated with marked reduction of the restenosis rate, with a Relative Risk Reduction (RRR) of $64 \%$ irrespective to the state and the condition of the arterial wall, length of the lesion or the revascularization strategy $[\mathbf{1 3 , 1 4}]$.

DEBATE-BTK study showed a low rate of limb loss and this could be assumed to several factors. First, the patients included in the study only after successful wire traversal of the lesion, therefore, it is not logic to compare the rate of limb loss in this study with other studies which were originally designed on an intention-to-treat basis. Also in this study, a dedicated multidisciplinary team was assigned to wound care for foot lesions and 
continuous surveillance regimen of vessel patency [14-17].

A meta-analysis study performed by Giacopo et al., has documented that the anti-restenotic benefits and value of DEB are consistent for either de novo or recurrent lesions, also it showed that there is no significant difference regarding mortality between treatment using DEB or plain uncoated balloon [18].

Liistro et al., reported markedly low one year restenosis rates in patients with infra-popliteal arterial disease treated with DEB and plain uncoated balloon of $27 \%$ versus $74 \%$ and also decreased occlusion rate $17 \%$ versus $55 \%$ in favor of DEB $[14,19]$.

The IN.PACT DEEP trial is a multicenteric randomized controlled trial targeted mainly to assess the effectiveness of Amphirion drug-eluting balloons (IA-DEB) in comparison to standard plain uncoated balloon within the CLI patients having infra-popliteal disease. The 1ry efficacy endpoints after one year were Clinically Driven Target Lesion Revascularization (CD-TLR) and Late Lumen Loss (LLL). The 1ry safety endpoints after 6 months were all-causes of mortality, major limb amputation or loss and TLR [3].

The primary efficacy results of IA-DEB versus standard angioplasty in the IN.PACT DEEP trial were CD-TLR of $9.2 \%$ versus $13.1 \%$ and LLL of $0.61 \pm 0.78 \mathrm{~mm}$ versus $0.62 \pm 0.78 \mathrm{~mm}[3]$.

While the primary safety endpoints were $17.7 \%$ versus $15.8 \%$. Major limb loss or amputations through one year was observed in the IA-DEB arm versus the standard angioplasty arm $8.8 \%$ vs. $3.6 \%$. And for these obvious consequences the IN.PACT Amphirion DEB product was retrieved from the market [3]

Table (3): One year efficacy end point of IN.PACT DEEP trial.

\begin{tabular}{llll}
\hline Item & IA-DEB & \multicolumn{1}{c}{ PTA } & $p$-value \\
\hline Late lumen loss*mm & $0.605 \pm 775$ & $0.616 \pm 781$ & 0.950 \\
Binary re-stenosis & $41(25 / 61)$ & $35.5(11 / 31)$ & 0.609 \\
Occlusion rate & $11.5(7 / 61)$ & $16.1(5 / 31)$ & 0.531 \\
CD-TLR (AFS) & $9.2(18 / 196)$ & $13.1(14 / 107)$ & 0.291 \\
CD-TLR (ITT) & $11.9(27 / 226)$ & $13.5(15 / 111)$ & 0.682 \\
\hline
\end{tabular}

AFS: Amputations Free Survival.

ITT : Intention to Treat.
Table (4): 1ry \& 2ry safety endpoints for IN.PACT DEEP trial.

\begin{tabular}{|c|c|c|c|}
\hline Item & IA-DEB & Plain balloon & $p$-value \\
\hline $\begin{array}{l}\text { 6-month 1ry safety } \\
\text { endpoint }\end{array}$ & $17.7(41 / 232)$ & $15.8(18 / 114)$ & 0.021 \\
\hline $\begin{array}{l}\text { One year major } \\
\text { limb amputation }\end{array}$ & $8.8(20 / 227)$ & $3.6(4 / 111)$ & 0.080 \\
\hline $\begin{array}{l}\text { One year all causes } \\
\text { of mortality }\end{array}$ & $10.1(23 / 227)$ & $8.1(9 / 111)$ & 0.551 \\
\hline $\begin{array}{l}\text { One year death \& } \\
\text { amputations }\end{array}$ & $35.2(80 / 227)$ & $25.2(28 / 111)$ & 0.064 \\
\hline $\begin{array}{l}\text { One year death, } \\
\text { major limb } \\
\text { amputation or } \\
\text { CD-TLR }\end{array}$ & $26.9(61 / 227)$ & $23.4(26 / 111)$ & 0.496 \\
\hline $\begin{array}{l}\text { Amputation free } \\
\text { survival }\end{array}$ & $81.1(184 / 227)$ & $89.2(99 / 111)$ & 0.057 \\
\hline
\end{tabular}

The IN.PACT DEEP trial was unsuccessful to achieve its 1ry efficacy endpoints regarding the superiority of IA-DEB in comparison to standard angioplasty. The 1ry and 2ry endpoints demonstrated nearly insignificant differences in results between the two study groups. And these findings demonstrates that DEB lack the effect of lowering restenosis on the long run despite its marvelous early results, also these observations supports the assumption that not only the arterial supply is the only factor that determine the end outcome, but there is multiple factors are incriminated in the complex pathophysiology of CLI and subsequently affect the clinical outcome $[3,19,20]$.

With the rapid evolution of endovascular technology, the future of the DEB could be a little bit more promising. Based on the results emerged from randomized trials in the femoro-popliteal segment and BTK arteries, a strong evidence is created to suggest the future superiority of DEB over plain uncoated balloon and many investigators forecast that other studies will be delivered to support the use of DEB inn this district.

\section{Conclusion:}

The early and mid-term results following infrapopliteal arterial angioplasty using DEB regarding the re-stenosis rate are significantly low which in turn decrease the need for re-do interventions.

However, the available randomized trials for patients with infra-popliteal arterial disease, endovascular intervention with DEBs compared with uncoated balloons shows nearly the same clinical efficacy and similar angiographic findings at 12 months, which raise the need for further trials but with extended follow-up periods and with larger 
sample size of the included patients to address precisely the exact role of DEBs in this field.

\section{References}

1- CONTE M.S., GERAGHTY P.J., BRADBURY A.W., et al.: Suggested objective performance goals and clinical trial design for evaluating catheter-based treatment of critical limb ischemia. J. Vasc. Surg., 50: 1462-73, 2009.

2- Ouriel K.: Peripheral arterial disease. Lancet, 358: $1257-$ 64, 2001.

3- ZELLER T., BAUMGARTNER I., SCHEINERT D., BRODMANN M., BOSIERS M., MICARI A., PEETERS P., VERMASSEN F., LANDINI M., SNEAD D.B., KENT K.C. and ROCHA-SINGH K.J.: Drug-Eluting Balloon versus Standard Balloon Angioplasty for Infra-popliteal Arterial Revascularization in Critical Limb Ischemia. 12Month Results From the IN.PACT DEEP randomized trial. Journal of the American College of Cardiology, Vol. 64, No. 15, 1568-76, 2014.

4- TASC Steering Committee, JAFF M.R., WHITE C.J., HIATT W.R., et al.: An update on methods for revascularization and expansion of the TASC lesion classification to include below-the-knee arteries: A supplement to the inter-society consensus for the management of peripheral arterial disease (TASC II). Journal of Endovascular Therapy, 22 (5): 663-77. Doi: 10.1177/1526602815592206, 2015.

5- UNVERDORBEN M., VALLBRACHT C., CREMERS B., et al.: Paclitaxel-coated balloon catheter versus paclitaxel-coated stent for the treatment of coronary in-stent restenosis. Circulation, 119 (23): 2986-94, 2009.

6- TOLVA V., CASANA R., HUIBERS A., PARATI G., BIANCHI P., CIRENI L., FERRERO E. and HALLIDAY A.: The Mid-Term Clinical Follow-Up Using Drug-Eluting Balloons on Tibial Artery "De Novo" Lesions in Patients With Critical Limb Ischemia: A Cohort Study, 50: 3048, 2016.

7- FUSARO M., CASSESE S. and NDREPEPA G., et al.: Drugeluting stents for revascularization of infrapopliteal arteries: Updated meta-analysis of randomized trials. J. Am. Coll. Cardiol. Intv., 6: 1284-93, 2013.

8- CASSESE S., NDREPEPA G., LIISTRO F., FANELLI F., KUFNER S., OTT I., LAUGWITZ K., SCHUNKERT H., KASTRATI A. and FUSARO M.: Drug Coated Balloons for Revascularization of Infrapopliteal Arteries A Meta-Analysis of Randomized Trials. JACC: Cardiovascular Interventions, Vol. 9, No. 10, 1072-80, 2016.

9- BYRNE R.A., JONER M., ALFONSO F. and KASTRATI A.: Drugcoated balloon therapy in coronary and peripheral artery disease. Nat. Rev. Cardiol., 11: 13-23, 2014.

10- CASSESE S., BYRNE R.A., OTT I., et al.: Paclitaxel coated versus uncoated balloon angioplasty reduces target lesion revascularization in patients with femoropopliteal arterial disease: A meta-analysis of randomized trials. Circ. Cardiovasc. Interv., 5: 582-9, 2012.

11-TROUTMAN D.A., MADDEN N.J., DOUGHERTY M.J. and CALLIGARO K.D.: Duplex ultrasound diagnosis of failing stent grafts place for occlusive disease. J. Vasc. Surg., 60 (6): 1580-4, 2014.

12- SCHMIDT A., ULRICH M., WINKLER B., et al.: Angiographic patency and clinical outcome after balloonangioplasty for extensive infrapopliteal arterial disease. Catheter Cardiovasc. Interv., 76: 1047-54, 2010.

13- SCHMIDT A., PIORKOWSKI M., WERNER M., ULRICH M., BAUSBACK Y., BRÄUNLICH S., ICK H., SCHUSTER J., BOTSIOS S., KRUSE H., VARCOE R. and SCHEINERT D.: First Experience with Drug-Eluting Balloons in Infrapopliteal Arteries Restenosis Rate and Clinical Outcome, Vol. 58, No. 11, 1105-9, 2011.

14- LIISTRO F., PORTO I., ANGIOLI P., GROTTI S., RICCI L., DUCCI K., FALSINI G., VENTORUZZO G., TURINI F., BELLANDI G. and BOLOGNESE L.: Drug-Eluting Balloon in peripherAl inTErvention for Below the Knee Angioplasty Evaluation (DEBATE-BTK): A Randomized Trial in Diabetic Patients with Critical Limb Ischemia. Circulation AHA, Vol. 128, No. 6, Page 615-21, 2013.

15- LIISTRO F., ANGIOLI P., GROTTI S., BRANDINI R., PORTO I., RICCI L., TACCONI D., DUCCI K., FALSINI G., BELLANDI G. and BOLOGNESE L.: Impact of critical limb ischemia on long term cardiac mortality in diabetic patients undergoing percutaneous coronary revascularization. Diabetes Care, 36: 1495-500, 2013.

16- ALEXANDRESCU V., HUBERMONT G., COESSENS V., PHILIPS Y., GUILLAUMIE B., NGONGANG C., VINCENT G., AZDAD K., LEDENT G., De MARRE C. and MACOIR C.: Why a multidisciplinary team may represent a key factor for lowering the inferior limb loss rate in diabetic neuro-ischaemic wounds: Application in a departmental institution. Acta. Chir. Belg., 109: 694$700,2009$.

17- LARSSON J., APELQVIST J., AGARDH C.D. and STENSTROM A.: Decreasing incidence of major amputation in diabetic patients: A consequence of a multidisciplinary foot care team approach? Diabet. Med., 12: 770-6, 1995.

18- GIACOPPO D., CASSESE S., HARADA Y., COLLERAN R, MICHEL J., FUSARO M., KASTRATI A. and BYRNE R.A.: Drug coated balloon Vs. plain balloon angioplasty for the treatment of femoropopliteal artery disease. An updated systematic review and meta-analysis of randomized clinical trials. JACC: Cardiovascular Interventions, Vol. 9, No. 16, 1731-42, 2016.

19- BRADBURY A.W., ADAM D.J., BELL J., et al.: For the BASIL trial Participants: Bypass versus Angioplasty in Severe Ischemia of the Leg (BASIL) trial: Analysis of amputation free and overall survival by treatment received. J. Vasc. Surg., 51: 18-31, 2010.

20- RASTAN A., BRECHTEL K., KRANKENBERG H., et al.: Sirolimus-eluting stents for treatment of infrapopliteal arteries reduce clinical event rate compared to bare-metal stents: Long-term results from a randomized trial. J. Am. Coll. Cardiol., 60: 587-91, 2012.

21- CORTESE B., GRANADA J.F., SCHELLER B., SCHNEIDER P.A., TEPE G., SCHEINERT D., GARCIA L., STABILE E., ALFONSO F., ANSEL G. and ZELLER T.: Drug coated balloon treatment for lower extremity vascular disease intervention: An international positioning document. European Heart Journal, Vol. 37, Issue 14: 1096$103,2016$. 
22- SCHELLER B., SPECK U., ABRAMJUK C., BERNHARDT U., BÖHM M. and NICKENIG G.: Paclitaxel balloon coating, a novel method for prevention and therapy of restenosis. Circulation, 110: 810-4, 2004.

23- CREMERS B., MILEWSKI K., CLEVER Y.P., ABOODI M.S., BIEDERMANN M., THIM T., KELSCH B., KALUZA G.L., SCHELLER B. and GRANADA J.F.: Longterm effects on vascular healing of bare metal stents delivered via paclitaxel-coated balloons in the porcine model of restenosis. Catheter Cardiovasc. Interv., 80: 603-10, 2012.

24- BALAKRISHNAN B., DOOLEY J.F., KOPIA G. and EDELMAN E.R.: Intravascular drug release kinetics dictate arterial drug deposition, retention, and distribution. J. Control Release, 123: 100-8, 2007.

25- AXEL D.I., KUNERT W., GÖGGELMANN C., OBERHOFF M., HERDEG C., KÜTTNER A., WILD D.H., BREHM B.R., RIESSEN R., KÖVEKER G. and KARSCH K.R.: Paclitaxel inhibits arterial smooth muscle cell proliferation and migration in vitro and in vivo using local drug delivery. Circulation, 96: 636-45, 1997.

26- TEPE G., ZELLER T., ALBRECHT T., HELLER S., SCHWARZWÄLDER U., BEREGI J.P., CLAUSSEN C.D., OLDENBURG A., SCHELLER B. and SPECK U.: Local delivery of paclitaxel to inhibit restenosis during angioplasty of the leg. N. Engl. J. Med., 358: 689-99, 2008.

\title{
دراسة للمتابعة قصيرة ومتوسطة المدى لحالات ألأب رأب شرايين

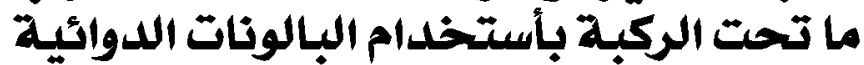

\author{
نظراً لارتفاع معدلات الاصابة بأمراض تصلب الشرايين وارتباطها الوثيق بالعديد من الأمراض الثائعة كالسكرى وارتفاع ضغط الدام.

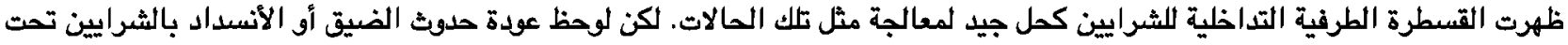

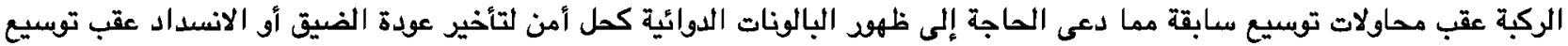 \\ الثراين. \\ في هذه الدراسة نستعرض المتابعة قصيرة ومتوبطة المدى لتوبيع شرايين تصت الركبة بأستخدام البالونات الدوائية. حيث وجد أنها

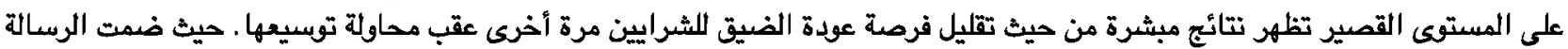

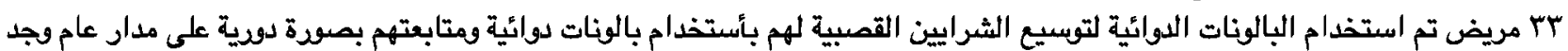

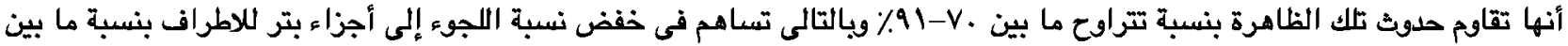

